\title{
INTERNATIONAL LAW
}

\section{The Legal Framework for Canada-United States Trade Edited by Maureen Irish and Emily F. Carasco}

In this work 15 leading authorities from Canada and the U.S. analyze issues related to the topic of free trade. They examine methods of implementing any new agreement, the roles of provinces and states, mechanisms available for dispute settlement, and much more.

$\begin{array}{llr}\text { L459-39960 } & \text { April } 1987 & 314 \mathrm{pp} \\ \text { hardcover } & & \$ 68.00\end{array}$

\section{Canadian Regulation of International Trade and Investment \\ Robert K. Paterson - Contributing Authors: Jock A. Finlayson, Philip Raworth \& Malcolm Smith}

Leading experts on international business law provide a full textual analysis of

- Canada's laws governing international trade and investment

- Canada's obligations under treaties and international accords including the GATT

- Important legal \& political issues you must consider when trading or investing abroad

- International trade regimes of Canada's major trading partners - the U.S., Japan \& the E.E.C.

$\begin{array}{lll}\text { LA59-39160 } & \text { November } 1986 & \mathbf{4 7 0} \mathbf{p p} . \\ \text { hardcover } & & \$ 78.00\end{array}$

\section{Review of International Business Law Editor-in-Chief: Errol P. Mendes}

This new journal offers a North American perspective on legal issues arising from the increase in international business and the trade across the U.S.-Canadian border. These issues are addressed in articles, updates, case comments and book reviews.

Prepared by legal and international business experts, REVIEW OF INTERNATIONAL BUSINESS LAW will be published three times a year. Take this opportunity to stay up-to-date on international business law.

Subscription (Three issues yearly including bound volume at the end of the year)

$\$ 90.00$

Books available for a 30-day free examination. A sample copy of subscription items available on request. To order, call or write:

Toronto $\bullet$ Calgary $\bullet$ Vancouver $\bullet$ Ottawa 


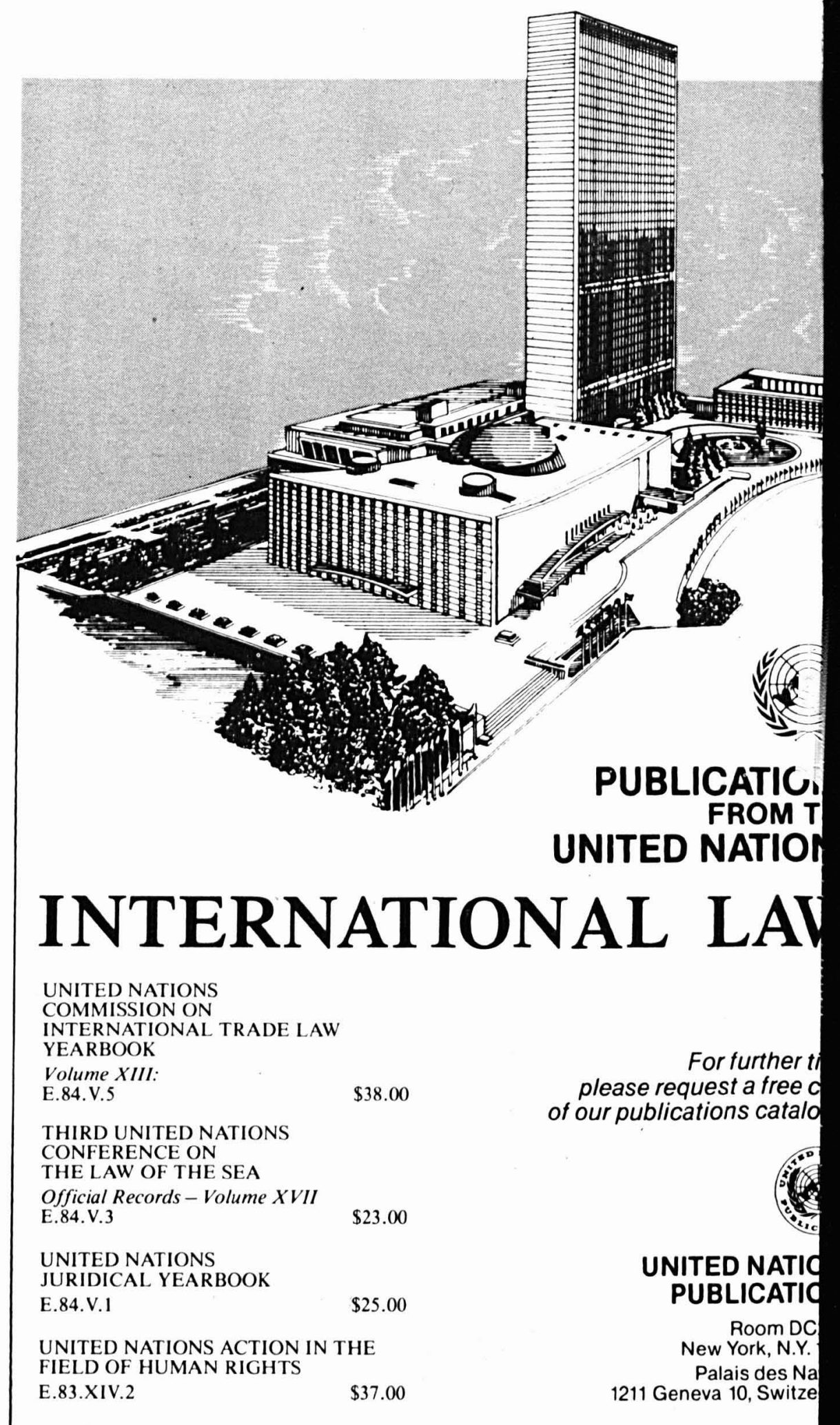

